\title{
LAZER E ACAMPAMENTOS DE FÉRIAS: ANÁLISE DE CURRÍCULOS DE FORMAÇÃO PROFISSIONAL
}

\author{
Leisure and vacation camps: \\ analysis of professional training curriculums
}

\begin{abstract}
RESUMo Este estudo objetivou descrever e analisar o currículo dos cursos de formação oferecidos por dois acampamentos de férias, realizados como parte das atividades do processo de seleção e formação de profissionais. A pesquisa documental foi feita a partir do material distribuído aos participantes dos cursos e a de campo foi realizada em dois acampamentos de férias por meio da observação estruturada e de entrevistas semiestruturadas com os responsáveis por ministrar os cursos. Os acampamentos buscam um perfil de profissionais jovens, recém ingressos nas universidades e que possuem tempo disponível. Os cursos têm uma estrutura curricular semelhante, nos quais módulos teóricos e práticos são abordados separadamente.
\end{abstract}

Palavras-chave: Lazer. Formação Profissional. AcampamenTOS DE FÉRIAS. CURRÍCULO.

ABstract We aimed to describe and analyze the professional training courses offered by two vacation camps, carried out as part of their activities in their professional selection process. The documentary research was made using material distributed to participants during the period of professional training courses and the field research was conducted through structured observation and semi-structured interviews with those responsible for administering the courses. Both camps seek the same type of professionals: young freshmen in universities who have time available for the work, which is carried out through participation in a traineeship. It was identified that the professionals responsible for organizing the courses have different ways of offering leisure. Furthermore, it was found that both courses have a similar curriculum, which includes theoretical and practical modules offered separately.

Key-Words: Leisure. Professional Qualification. VAcation CAMPS. CURRICULUM.

\section{INTRODUÇão}

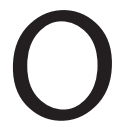

s acampamentos de férias são instituições privadas, filantrópicas ou organizações não governamentais que oferecem aos participantes vivências articuladas com diversos campos do conhecimento. São locais onde os sujeitos têm a oportunidade de conviver e trocar experiências com pessoas de faixas etárias e locais diferentes, saindo da rotina das cidades. Os
Gustavo Schunemann Christofaro Silva ${ }^{\mathrm{I}}$ IUniversidade Federal de Minas Gerais (UFMG), Belo Horizonte/MG - Brasil.

Helder Ferreira Isayama ${ }^{\text {II }}$ II Universidade Federal de Minas Gerais (UFMG), Belo Horizonte/MG - Brasil.

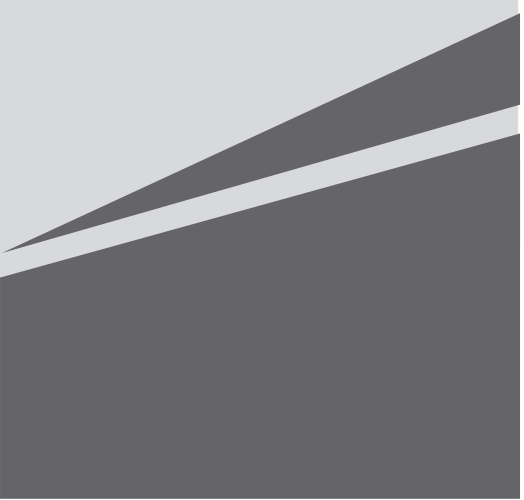


acampamentos contam, na maioria das vezes, com a atuação de profissionais e estudantes de várias áreas, o que pode garantir ao acampante vivências práticas e o conhecimento de conteúdos culturais. Tratam-se, segundo Camargo (1979), de equipamentos específicos de turismo social não urbano que, nos últimos anos, "transformaram-se em mais uma das opções para crianças e adolescentes das classes mais privilegiadas viajarem seja nas férias ou em outro período do ano, realizando jogos, brincadeiras e passeios em contato com a natureza" (STOPPA, 1999, p. 28).

A atividade acontece de forma periódica e com duração que pode variar de dias a semanas. Refeitórios, banheiros coletivos, dormitórios, ginásios, piscinas e outros espaços compõem essa infraestrutura, que, aliada à ação de animadores socioculturais responsáveis por planejar, executar e avaliar as atividades desenvolvidas, caracterizam esse equipamento de lazer.

Em Eells (1986), encontramos a definição de acampamento como uma experiência uniforme e/ou sistemática que fornece oportunidades criativas, recreativas e educativas para o grupo, e que contribui para o crescimento mental, físico, social e espiritual de cada acampante.

Apesar de considerarmos que os acampamentos de férias são espaços para a convivência e troca de experiências entre os participantes (quer acampantes quer profissionais), concordamos com Stoppa (1999, p. 34), de acordo com o qual a forma de atuação profissional utilizada "necessita de uma melhor reflexão e discussão". Muitas vezes entendidos como extensão da escola, os acampamentos de férias deveriam levar em consideração a estruturação de sua ação profissional como espaço para a educação não-formal. Segundo Henriques (2004), essa vinculação com a educação nos faz supor que as atividades desenvolvidas nesses equipamentos possuem um objetivo e um propósito a ser alcançado. Por isso, a formação profissional é um tema que merece aprofundamentos quando abordamos os acampamentos de férias.
Escolhemos, portanto, a discussão sobre a formação profissional em lazer como temática e utilizamos dos estudos curriculares como pano de fundo para a discussão. Nesse sentido, acreditamos que o conhecimento que constitui o currículo está irremediavelmente inserido nos processos de formação pelos quais nos tornamos o que somos.

No contexto da formação profissional em lazer, apesar das diferenças conceituais entre os estudiosos, existe uma tendência, na atualidade, em compreender o lazer como uma "dimensão da cultura" (GOMES, 2008, p. 3). Dessa forma, é no campo da cultura que se encontra a possibilidade de conexões produtivas entre lazer (e sua formação profissional) e currículo, pois entendemos o currículo como uma prática cultural, que, segundo $\mathrm{Pa}$ raíso (2010):

...divulga e produz significados sobre o mundo e as coisas do mundo; como um espaço privilegiado de contestação, conflitos e negociações culturais; como território em que as diferentes culturas existentes são representadas de modo desigual; como campo em que os diferentes grupos culturais constroem suas identidades (p. 33).

Um currículo circula por vários espaços, não se limitando apenas às políticas curriculares, escolas, universidades ou faculdades de educação. Nesse sentido, entendemos os currículos escolares e não escolares como práticas culturais importantes na produção e na divulgação de conhecimentos e significados. $O$ entendimento de currículo também pode basear-se em seu sentido etimológico, "significando pista de corrida, que veio para o campo pedagógico para ordenar e controlar as atividades educacionais, dando uma estruturação para essas atividades" (PARAíso, 2010, p. 30), ou, no mundo contemporâneo, ser concebido com menos ênfase em sua estrutura (a pista da corrida) do que na forma como se lida com essa estrutura. Silva (2013, 
p. 15) ainda complementa, afirmando que o currículo se relaciona com as trajetórias de vida, e postula que "no curso dessa corrida que é o currículo, acabamos por nos tornar o que somos".

Dessa forma, podemos notar que o currículo é caracterizado como algo inventado, e que, muitas vezes, nos esquecemos de explorar sua feitura. É nesse contexto que destacamos o papel dos profissionais do lazer, que ao se transformarem em analistas culturais, "podem assumir a tarefa de mostrar o funcionamento dos artefatos culturais, criar novos significados para esses campos e colocar em questão o que está sendo ensinado pelos diferentes currículos (escolares e não escolares) existentes" (PARAísO, 2010, p. 30).

O entendimento de currículo vai para além do âmbito do conhecimento, sendo uma questão de identidade.

Procuramos abordar questões que conectam currículo e formação profissional em lazer e que são fundamentais para se pensar no objetivo que este trabalho propõe-se a alcançar. Os processos de formação para a atuação nos acampamentos de férias são oferecidos, geralmente, pelas próprias instituições e têm duração média de um fim de semana. São denominados "cursos de formação", "curso de monitoria em acampamento", "treinamento de monitoria em acampamento". Normalmente, os sujeitos interessados precisam ser maiores, bem como, arcar com as despesas financeiras, como inscrição, transporte, alimentação e hospedagem durante o período de realização da formação.

Consideramos importante a reflexão a respeito dos acampamentos de férias, entendidos como equipamentos específicos de lazer, sobretudo em relação aos currículos dos cursos de formação profissional oferecidos por essas instituições. A partir disso, o objetivo deste trabalho foi o de descrever e analisar o currículo dos cursos de formação oferecidos por dois acampamentos de férias, realizados como parte das atividades do processo de seleção de seus profissionais. Na tentativa de descobrir o que o currículo desses cursos almeja, buscamos identificar, além das estratégias metodológicas utilizadas, os conteúdos, as dinâmicas de trabalho e os objetivos dos cursos.

\section{Percurso metodológico}

Este estudo buscou analisar os cursos de formação profissional oferecidos pelos acampamentos de férias pertencentes à Associação Brasileira de Acampamentos Educativos (ABAE), realizados como parte das atividades do processo de seleção de seus profissionais. O primeiro contato com os 20 acampamentos pertencentes à associação foi feito via telefone e teve o intuito de investigar quais deles possuíam algum tipo de intervenção com o objetivo de formar seus profissionais. Após o contato via telefone, foi detectado que, dos 20 acampamentos associados, 11 não ofereciam esse tipo de intervenção.

Em um segundo momento, entramos em contato com os nove acampamentos que possuíam intervenções para a formação profissional. Entre as nove instituições, seis não aceitaram participar da pesquisa, alegando não ter interesse em colaborar com o estudo. Em um dos três acampamentos que aceitaram participar, a realização da pesquisa não foi possível, pois a formação, que acontece apenas uma vez no ano, havia sido feita antes do período provido para a coleta de dados.

Dessa forma, o trabalho combinou as pesquisas bibliográfica, documental e de campo. A pesquisa documental foi feita a partir do material distribuído aos participantes no período dos cursos de formação, como folders, apostilas e manuais que contemplavam conteúdos dos cursos, história dos acampamentos, programação, avaliação, objetivos.

A pesquisa de campo foi realizada por meio da observação estruturada e de entrevistas semiestruturadas com os responsáveis por ministrar os cursos. A observação estruturada se deu de forma planejada e todas as informações coletadas foram registradas em caderno de campo. Por fim, foi feita a observação das estratégias metodológicas e da dinâmica do trabalho ao longo do curso. 
A escolha dos profissionais responsáveis por ministrar os cursos de formação, dos diretores gerais dos acampamentos e da equipe de psicologia, como sujeitos a serem entrevistados, deu-se por terem uma função central no desenvolvimento da formação nos acampamentos, sendo os responsáveis por criar, modificar e organizar o currículo desses cursos de formação. Seguindo um roteiro previamente elaborado, as entrevistas semiestruturadas foram feitas mediante carta de apresentação da pesquisa, a qual continha objetivos, finalidades e métodos. Vale ressaltar que a realização da pesquisa só tornou-se possível mediante a aprovação pelo COEP Comitê de Ética em Pesquisa.

O tratamento das informações coletadas foi ancorado na análise de conteúdo, fundamentada por Triviños (1987).

\section{AS AÇÕES DE FORMAÇÃO: CONTEXTUALI- ZAÇÃO, ORGANIZAÇÃO E OBJETIVOS}

$\mathrm{Na}$ tentativa de compreender o contexto que permeia os cursos de formação profissional oferecidos pelos acampamentos, bem como, sua organização e funcionamento, foi necessário conhecer as etapas do processo de formação. Aos entrevistados, responsáveis diretos pelo desenvolvimento da formação profissional nos acampamentos, foram atribuídos códigos com o intuito de assegurar o seu anonimato. Os entrevistados do Acampamento 1 receberam os códigos E1 e E2 e os entrevistados do Acampamento 2 os códigos E3, E4 e E5.

O curso de formação profissional realizado pelo Acampamento 1 acontece duas vezes ao ano, uma em cada semestre, geralmente antes das temporadas de férias, que acontecem nos meses de janeiro e julho. O curso, que está em sua 49. edição, tem a duração de três dias e não tem custos para os participantes, com exceção do deslocamento até o acampamento. Pensão completa, que inclui alimentação e hospedagem, é de responsabilidade do acampamento. As inscrições são feitas através do site do acampamento, onde o candidato envia seu currículo e, após uma avaliação realizada pela equipe responsável, é convidado (ou não) para participar do curso.

Ao chegarem ao acampamento no dia do curso, todos os participantes realizam um credenciamento onde são informados sobre a programação e direcionados às suas dependências. Separados por sexo, os participantes ficam hospedados nos mesmos dormitórios que são utilizados para alojar as crianças e jovens que participam de eventos durante o ano. Após o credenciamento, os participantes recebem uma pasta que contém o material utilizado durante o curso, são eles: apostila denominada "O monitor: Funções e preparos"; ficha de avaliação do curso; carta de apresentação de monitoria, na qual os participantes escrevem uma síntese de seu perfil e o porquê da vontade de trabalhar como monitor do acampamento; ficha médica, utilizada como anamnese dos participantes (CADERNO DE CAMPO, 2015).

Diferentemente do Acampamento 1, o curso de formação profissional oferecido pelo Acampamento 2 é exclusivo para monitores ativos da empresa. Denominado "Prolíder Programa de Formação de Liderança”, o curso é promovido e realizado pelo acampamento, com o intuito de complementar o desenvolvimento profissional dos monitores do seu quadro de profissionais. A partir do nome dado ao curso, percebe-se que o Acampamento 2 norteia-se por aspectos de liderança como base para a formação de seus profissionais. Esse fato torna-se mais claro a partir da justificativa do curso apresentada: "proporcionar aos jovens monitores ativos em seu quadro, incentivo, ferramentas e treinamento para o desenvolvimento de habilidades e competências, necessários no exercício de liderança eficaz" (MANUAL, 2015, p. 6).

O curso, que tem a duração de três dias, acontece uma vez ao ano e é dividido em duas etapas: uma no primeiro semestre e a outra no segundo. Pelo fato de ser destinado aos profissionais da instituição, trata-se de um curso fechado, e os participantes, além de não terem despesas, são remunerados pela participação. 
Como acontece no curso do Acampamento 1, os participantes também são separados por sexo e se hospedam nas dependências do próprio acampamento, as mesmas utilizadas pelas crianças e jovens durante as temporadas. Ao chegarem para o curso, os participantes recebem uma apostila com o seguinte conteúdo: 1) programação do curso; 2) apresentação do acampamento; 3) apresentação do curso e instruções gerais para contratação de serviços eventuais em monitoria; 4) regimento interno; 5) procedimentos de rotina e atividades; 6) procedimento operacional nas atividades de rotina do dia; 7) procedimentos operacionais nas atividades de livre escolha e orientações de segurança (MANUAL, 2015).

Percebemos que ambos os cursos possuem modelos de trabalho e organização semelhantes. O mesmo acontecia no início das atividades dos acampamentos, quando ainda não existiam eventos exclusivos para a capacitação de seus profissionais:

A formação acontecia dentro das temporadas de férias. Nós ficávamos, historicamente, 30 dias. A gente acabava conhecendo muito as pessoas. Dentro desse grupo eram tirados uns. Ele era eleito pelo próprio grupo de monitores. Os monitores avaliavam ele durante os 30 dias para ver se ele tinha condições para passar a ser monitor (E3).

Então isso sempre foi básico antes mesmo de ter curso. A gente trazia estagiários e ficavam juntos com monitores que já eram da equipe, que já eram pessoas de confiança nossa. Eles que avaliavam a prática dele durante as temporadas (E1).

Os responsáveis pelos dois acampamentos compartilham da ideia de que, naquela época, não existia preocupação com intervenção voltada para a formação profissional. Segundo eles, a demanda por eventos do acampamento era grande e não existia tempo disponível para ações de formação. Nesse sentido, concordamos com Trautmann (2001) quando afirma que o tempo de formação profissional não implica a redução do tempo de trabalho. O que deve estar em jogo é um coinvestimento na formação, a busca por maneiras de incentivar os profissionais a se comprometerem com projetos de formação que atendam tanto aos interesses dos profissionais como aos da empresa.

Não encontramos nos documentos o objetivo do curso oferecido pelo Acampamento 1. No entanto, o entrevistado E1 afirma que, por ser destinado a pessoas que desejam iniciar o trabalho de monitoria no acampamento, o curso tem como objetivo a seleção profissional, o treinamento e a capacitação da equipe.

O objetivo do curso é a seleção profissional para o nosso trabalho. Exclusivo para a nossa empresa. Treinar as pessoas para trabalharem dentro da nossa rotina. E trabalhar de forma que seja coerente com a filosofia da nossa empresa (E1).

O curso oferecido pelo Acampamento 2 não possui como objetivo a seleção profissional, mas "Possibilitar a formação de jovens líderes com capacidade de utilizar conceitos teóricos e práticos em benefício de um processo decisório eficiente, contribuindo na formação de crianças e adolescentes" (MANUAL, 2015, p. 6).

Notamos que ambos os cursos compartilham o objetivo de treinar e capacitar seus profissionais, porém a partir da estruturação de um currículo composto por um conjunto de saberes a serem transmitidos com o intuito de transformar, modificar, subjetivar e governar os sujeitos envolvidos:

O objetivo é formar os nossos monitores. Moldá-los da forma que queremos para o nosso acampamento. Então, através desse curso a gente quer que os nossos monitores tra- 
balhem dentro das diretrizes que nós escolhemos (E2);

O objetivo do treinamento é o de alinhar todos os procedimentos comportamentais e de operação de todos os monitores (E4).

Dois verbos utilizados nos chamaram a atenção nos trechos das entrevistas citadas: "moldar" e "alinhar". Ambos remetem à discussão do currículo como artefato cultural que forma determinados indivíduos, pois é através do currículo proposto pelos cursos de formação que os acampamentos buscam mudar condutas, produzir e construir o tipo de sujeito "adequado" para a atuação profissional. Nesse sentido, Tadeu (2003, p. 38) afirma que "todo currículo quer modificar alguma coisa em alguém". Porém, concordando com Paraíso (2010), acreditamos que seja fundamental refletir sobre a distância existente entre o sujeito que se deseja formar e os saberes utilizados para esse propósito. De acordo com a autora:

...esse tipo de sujeito que um currículo deseja produzir parece, muitas vezes, jargão sem sentido, já que não conseguimos sequer imaginar como os conteúdos, conhecimento, temas e disciplinas que são selecionados para formar o "tal sujeito" demandado pelo currículo poderão produzir os efeitos desejados (PARAísO, 2010, p. 48).

A partir da análise das falas dos entrevistados, detectamos divergência no que se refere ao motivo pelo qual os cursos foram criados. Enquanto o curso do Acampamento 1 foi criado por causa da dificuldade em encontrar mão de obra qualificada para atuar no campo, o curso oferecido pelo Acampamento 2 teve a sua criação relacionada ao aumento da demanda de serviços e pela necessidade de capacitação de uma equipe maior:

O acampamento sempre foi, desde que eu comecei e até hoje uma atividade ainda não reconhecida no Brasil. Então você não tem um curso especializado. Você quer abrir um hospital, você contrata medico, você quer fazer uma empresa de engenharia, você contrata engenheiro, você tem profissionais especializados para trabalhar nisso (E1).

O quê que aconteceu... a demanda do acampamento começou a crescer muito e a necessidade de monitoria também. Aí entrou todos os problemas que isso envolve. Conforme a coisa aumentou e precisamos ter mais monitores trabalhando, surgiu a necessidade de ter um treinamento para toda a equipe (E4).

O aspecto apresentado pelo entrevistado E1 nos faz refletir sobre as ações de formação ofertadas no Brasil em diversos níveis. Diferentes possibilidades de formação de profissionais para atuar no âmbito do lazer são mais frequentes em nosso país. Isayama (2010) nos alerta que, além dos cursos de graduação específicos acerca do lazer, ofertados desde 1998 em nosso país, existe, na atualidade, a possibilidade da realização de pós-graduação lato e stricto sensu a respeito do tema. Santos (2011) apresenta uma lista de cursos técnicos em lazer e Melo e Alves Junior (2003) nos mostram que outra possibilidade de formação na área é vislumbrada nos inúmeros grupos de estudo/pesquisa criados em faculdades, escolas, departamentos e cursos espalhados pelo Brasil. Além disso, eventos técnico-científicos também constituem outra rica possibilidade de formação profissional no campo do lazer, entre eles: O Encontro Nacional de Recreação e Lazer (ENAREL) e o Congresso Brasileiro de Estudos do Lazer (CBEL) (ISAYAMA, 2010).

A apresentação dos cursos de formação profissional oferecidos pelos acampamentos participantes desta pesquisa nos permitiu compreender de forma substancial seus contextos, objetivos e estrutura organizacional. 


\section{Perfil PROfissional almejado: CRITÉ- RIOS DE SELEÇÃO E AVALIAÇÃO}

Concordamos com Paraíso (2010, p. 28) quando afirma que "todo currículo quer formar, produzir ou construir um tipo de sujeito". Nesse sentido, percebemos que os acampamentos participantes da pesquisa possuem um perfil profissional desejado, responsável por nortear sua organização curricular e fundamentar suas ações. Detectamos que ambos os acampamentos buscam o mesmo perfil profissional para compor o seu quadro de funcionários:

O público alvo são universitários. De preferência os estudantes mais novos, que possuem tempo de sobra (E1).

Indivíduo recém ingresso na universidade e que nos primeiros anos de faculdade pode usufruir deste momento (E3).

Notamos que o perfil almejado é o universitário, de preferência aqueles que estão no início dos cursos de graduação e possuem tempo disponível para a atuação nos acampamentos. Enquanto o Acampamento 2 não restringe a área de formação do sujeito para a participação no curso e atuação no acampamento, identificamos que existe divergência entre os organizadores do curso do Acampamento 1 no que se refere à preferência da área de atuação do candidato à vaga:

O público alvo são universitários da área que envolve ou o turismo ou a educação física. A gente não exclui outras áreas, mas as áreas principais são a educação física e o turismo (E1).

Os nossos melhores profissionais são os que não têm nada a ver com a área de educação física nem de turismo. Esses são nossos profissionais. Então damos preferência aos profissionais de áreas que não são essas (E2).
Cabe ressaltar que, apesar de o campo de formação profissional para o lazer estabelecer laços com a educação física, na atualidade é possível identificar iniciativas em diferentes áreas do conhecimento, como o turismo, a terapia ocupacional, a administração, a pedagogia, a economia e a hotelaria, que contribuem para a discussão sobre o lazer. No entanto, destacamos que essa relação entre a educação física e o lazer é histórica e, de acordo com Isayama (2002), vestígios disso podem ser encontrados baseados na valorização de conteúdos físico-esportivo nas atividades de lazer. De acordo com Melo e Alves Junior (2003), no Brasil do início do século XX, essa relação ganhou importância diante do quadro do operariado, no qual as atividades de lazer eram encaradas como instrumentos para a recuperação das forças de trabalho e como componentes da manutenção da saúde. Naquela época, o conjunto de atividades de lazer, entendidos como recreação, tinha o intuito de fortalecer, higienizar e moralizar os corpos. Por essa razão, o profissional de educação física era visualizado como o mais "habilitado" para atuar no âmbito do lazer, reforçando os laços entre as duas áreas.

Os trechos das entrevistas a seguir apresentam critérios estabelecidos pelos acampamentos como pré-requisitos para a participação nos cursos e atuação nos acampamentos. Esses critérios são obrigatórios, requisitos para autorizar a participação na ação de formação:

Você precisa ter também, para fazer o curso e depois o estágio, o atestado de antecedentes criminais, e um atestado médico que te autorize a participar de atividades físicas. Então são esses os pré-requisitos para a participação. Além, óbvio, de ser obrigatório ser maior de 18 anos (E1).

Precisa ser maior de idade. Não restringimos a formação acadêmica, mas precisa ter o ensino médio completo. Além disso a pessoa não pode morar longe do Acampamento (E5). 
Além disso, a partir da fala dos entrevistados, foi possível identificar algumas pistas do perfil profissional que se busca encontrar nos cursos:

Em relação à idade, entendemos que é um trabalho que exige um esforço físico. Pela nossa experiência, acima de 25, 26, 27 a gente já acha que não é uma fase de vida que a pessoa vai vir sem estar alinhado com plano de carreira. Precisamos de pessoas com disposição, que goste de criança (E5).

Você precisa que um monitor seja extremamente alegre, extremamente cativante, que seja extremamente bem aceito pela criança e que tenha paciência (E2).

Esses trechos nos fazem refletir sobre a visão de que o profissional que já vem pronto, pois eles colaboram com a ideia de que para atuar com o lazer não é preciso formação, e sim um “dom". Acreditamos que as experiências profissionais e pessoais de cada indivíduo não devem ser consideradas por si só. Além disso, concordamos com Santos (2011) quando afirma que:

...os saberes acadêmicos e os conhecimentos científicos são a base para se sair da atuação centrada no senso comum, pois, uma vez fundamentado, é possível encontrar brechas para intervir no campo do lazer, entendendo-o como um fenômeno amplo e complexo (p. 67).

De acordo com Stoppa (2000), o perfil profissional procurado para atuar com o lazer não está relacionado com a formação específica e aprofundada sobre a temática, mas relacionado à

...questão de aceitação da filosofia de trabalho do local, a questão da estética pessoal do candidato (delimitação de um determinado "padrão" de beleza) além da pessoa ou gostar de crianças, ou ser extrovertidas, causando, muitas vezes, uma grande confusão onde o bom profissional é associado à pessoa mais palhaça, engraçada, que procura em tudo fazer "graça" e a todos fazer cair na gargalhada (p. 177).

Por meio das conversas que mantivemos com os participantes ao longo dos cursos, detectamos que um grupo de sujeitos participava dos cursos por ter tido a experiência de estar no acampamento como acampante (CADERNO DE CAMPO, 2015).

A gente tem ex-acampantes e, tradicionalmente, o caminho de um ex-acampante que é apaixonado pelo acampamento é querer ser monitor (E1).

Esses são nosso profissionais. Por quê? Porque fazem o que gostam. Fazem por amor. Então se dedicam a isso (E2).

Outra questão que chamou a atenção foi a ideia de que a atuação dos profissionais nos acampamentos é baseada no amor pela atividade. Nesse aspecto, concordamos com Pinto (1995), que salienta que até hoje se pensa que, para atuar com lazer, é necessário que o indivíduo possua um "dom”. Assim, mesmo que formado em universidades ou em outras instituições, o indivíduo necessita, basicamente, de tolerância, animação e prazer pelo trabalho para executar sua ação. Dessa maneira, o perfil profissional baseia-se na cooperação e no amor ao trabalho assistencialista, e o futuro profissional pouco tem que aprender técnica, científica e pedagogicamente (ISAYAMA, 2010).

É possível perceber que, mesmo com estratégias diferenciadas, os critérios de seleção e avaliação profissional dos dois 
acampamentos estudados convergem. O modelo do profissional para atuar no segmento é aquele que é jovem, sabe se comunicar e é capaz de aplicar as atividades aprendidas ao longo dos cursos. Além disso, busca-se o profissional animado, tolerante e que ama o que faz.

Percebemos que ambos os acampamentos não têm uma preocupação ampliada com a formação do indivíduo, mas buscam um tipo de perfil "adequado" para compor o seu quadro de profissionais. Nesse sentido, acreditamos que os indivíduos são criações advindas de "tecnologias humanas" (ROSE, 2001) e uma dessas tecnologias é o currículo, entendido, conforme Paraíso (2010), como artefato que produz sujeitos, subjetividades ou identidades e que, ao mesmo tempo em que é capaz de formar e produzir modos de agir e de conduzir, modos de ser e estar no mundo, interfere, diretamente, na vida daqueles que com eles se ocupam e na vida daqueles com os quais eles se ocupam.

\section{ESTRUTURA CURRICULAR: ORGANIZAÇÃO, CONTEÚDO E PLANEJAMENTO}

Apoiados em Paraíso (2010), partimos do pressuposto de que o currículo é um campo aberto de significação, que contribui para a produção de sujeitos voltados para o questionamento e a crítica do que foi significado, sendo assim produzido e produtor. De acordo com a autora, o currículo é um "discurso que inclui e exclui, mostra, torna visível, hierarquiza, cria objetos e modela a realidade. É um texto que oferece ferramentas para ver, nomear, compreender e dar sentido ao mundo e às coisas do mundo, aos sujeitos e à cultura" (p. 42).

Entendemos o currículo como um discurso e um texto que analisa as questões de identidade e poder presentes nos mais diferentes artefatos e manifestações culturais, não se restringindo somente ao âmbito escolar. Um currículo não existe apenas nas políticas curriculares, nas escolas, nas faculdades de educação ou nas universidades. De acordo com Paraíso (2010), "um currículo circula por vários espaços, percorre-os, move-se neles e atravessa-os" (p. 37). Ao se deslocar, se desdobrar e se materializar, o currículo acontece também nas salas de aula, nas bibliotecas, nos museus, nas propostas político-pedagógicas, nas diferentes formações, na pesquisa educacional, na internet, nos jogos, nas brincadeiras, na mídia, na música, na cultura, nas práticas de lazer e em outros segmentos da vida.

Nesse sentido, ao acompanhar os cursos oferecidos pelos dois acampamentos, percebemos que ambos possuem uma estrutura curricular semelhante, pois as atividades são divididas em módulos práticos e teóricos. Nos dois cursos, os conteúdos desenvolvidos durante os módulos teóricos são ancorados nos materiais entregues aos participantes no início das atividades.

O módulo teórico do Acampamento 1, que acontece de forma intercalada com o prático, é dividido em cinco capítulos, com duração de uma hora e meia cada. As palestras, ministradas pelo diretor e coordenador, acontecem na sala audiovisual do acampamento, por meio da projeção de slides. O primeiro capítulo, ministrado pelo diretor do acampamento, é dividido em duas etapas (uma de manhã e outra à tarde) e é destinado à apresentação do acampamento. Na primeira etapa, são abordados tópicos referentes à história do acampamento, sua missão, os objetivos gerais e específicos, a metodologia utilizada na programação das temporadas e a apresentação da infraestrutura. No segundo, é apresentado o organograma da empresa, as funções e responsabilidades específicas de cada membro da equipe de monitoria e recreação do acampamento (CADERNO DE CAMPO, 2015).

Todos os outros capítulos são ministrados pelo coordenador geral de recreação e eventos, e são destinados à descrição detaIhada das funções dos monitores do acampamento. No segundo capítulo, são trabalhadas questões referentes ao perfil dos monitores, bem como, às atribuições e responsabilidades esperadas de cada um deles. De acordo com o documento analisado, o acampamento divide os profissionais em quatro "universos" de perfil: o responsável; o organizador (líder); o 
recreador e o educador (MONAC, 2015, p. 2). São apresentadas as características de cada grupo, bem como, as atribuições e as responsabilidades esperadas de cada um deles.

De acordo com o documento analisado, "para atuar de forma eficiente, algumas capacidades essenciais devem ser destacadas" (MONAC, 2015, p. 5). E é exatamente sobre essas capacidades que o terceiro capítulo se refere. As capacidades são separadas em quatro grupos nos quais questões específicas a respeito delas são discutidas. $O$ quadro a seguir foi elaborado com base nos dados do documento coletado em campo com o intuito de facilitar a compreensão e a visualização das capacidades e os conteúdos trabalhados em cada uma delas.

Quadro 1: Capacidade versus Conteúdos trabalhados - Acampamento Lúdico

\begin{tabular}{|l|l|}
\hline Capacidade & $\begin{array}{l}\text { Conteúdo } \\
\text { Trabalhado }\end{array}$ \\
\hline Condição física & $\begin{array}{l}\text { capacidade física } \\
\text { sono } \\
\text { alimentação } \\
\text { saúde } \\
\text { voz }\end{array}$ \\
\hline Condição psicológica & $\begin{array}{l}\text { céu ou inferno' } \\
\text { disposição }\end{array}$ \\
\hline Condição moral & $\begin{array}{l}\text { maturidade } \\
\text { valores pessoais }\end{array}$ \\
\hline Condição pedagógica & $\begin{array}{l}\text { características de } \\
\text { cada faixa etária } \\
\text { conhecimentos } \\
\text { gerais } \\
\text { vencer ou vencer } \\
\text { seja positivo } \\
\text { e entusiasta } \\
\text { justiça } \\
\text { respeito }\end{array}$ \\
\hline
\end{tabular}

Expressão utilizada pelos acampamentos pesquisados para discutir dinâmicas relacionadas ao campo da psicologia. O termo céu significa quando está tudo bem e inferno quando as coisas não andam bem. Por isso, para os gestores dos acampamentos, quando estão com as crianças, os monitores devem deixar de lado todas as questões extraacampamentos.
No quarto capítulo, são apresentadas as regras, normas e condutadas destinadas aos monitores do acampamento. São explanadas quinze regras, normas e condutas que os monitores devem seguir durante a atuação. São elas: 1) aparência; 2) postura geral; 3) contato físico; 4) exposição física; 5) exemplo; 6) colocação física; 7) presença, participação e atenção; 8) forma de se comunicar; 9) apelidos; 10) iniciativa; 11) disciplina; 12) relacionamento com o acampante; 13) relacionamento com os outros monitores; 14 ) relacionamento com as outras empresas e 15) diversos.

No quinto e último capítulo do módulo teórico, são desenvolvidas dicas aos monitores, no que tange aos seguintes temas: regras de quartos; conduta de quarto; cama e malas (arrumação e cuidados); roupas e cuidados com pertences; fiscais de quarto; banho; hora de dormir e fechamento da temporada.

O módulo prático, que é realizado pelos coordenadores de programação, é separado em dois momentos e acontece nas demais dependências do acampamento. Em um dos momentos, os participantes vivenciam algumas atividades recreativas que serão utilizadas nas temporadas (CADERNO DE CAMPO, 2015). O outro momento prático é destinado ao treinamento das condutas e procedimentos específicos para cada espaço e situação do acampamento. As condutas esperadas durante os procedimentos apresentados a seguir são explicadas nos próprios locais a que se referem: procedimento padrão de segurança para acidentes físicos (quedas, batidas etc.); procedimentos gerais de resgate em meio líquido (piscina e lago); procedimentos básicos para embarque; procedimentos básicos durante a viagem de ônibus; procedimentos básicos na chegada ao acampamento; procedimentos básicos no reconhecimento do acampamento; procedimentos básicos no quarto; procedimentos básicos na hora do banho; procedimentos básicos no horário do descanso e arrumação de quartos; procedimentos básicos no horário do fiscal do quarto; procedimentos básicos na hora de dormir; procedimentos básicos na hora de acordar; 
procedimentos básicos para as atividades em equipes; procedimentos básicos no horário livre; procedimentos básicos nas refeições; procedimentos básicos para o desembarque; procedimentos básicos das atividades e de segurança das atividades (CADERNO DE CAMPO, 2015).

O curso de formação oferecido pelo Acampamento 2 possui estrutura curricular semelhante e as atividades do curso também são divididas em módulos práticos e teóricos. O módulo teórico acontece no salão principal do acampamento e os conteúdos são ministrados pelo diretor-geral e pelo gerente geral do acampamento, por meio de apresentações em slides (CADERNO DE CAMPO, 2015). Intercalados com o módulo prático, os conteúdos teóricos que são desenvolvidos junto aos participantes, durante os três dias de curso, são separados em quatro capítulos com duração de uma hora e meia cada.

O primeiro capítulo é destinado à abertura do treinamento. $O$ diretor-geral do acampamento inicia a fala com um discurso de boas-vindas aos participantes e, em seguida, expõe a história do acampamento (CADERNO DE CAMPO, 2015). Ao final da apresentação o diretor-geral aborda os seguintes temas: 1) objetivos do curso; 2) programação do curso; 3) organograma das unidades: são expostos os cargos e setores que compõem a equipe do acampamento. Além disso, são explicadas questões referentes ao processo de contratação, à remuneração, à promoção e à avaliação de desempenho; 4) calendário das unidades do acampamento: nesse momento, são informados todos os eventos que acontecerão ao longo do ano nas duas unidades do acampamento (MANUAL, 2015).

O segundo capítulo destina-se à apresentação dos serviços oferecidos pela acampamento 2 unidade 2. Nesse momento, são expostas questões referentes ao conteúdo, organização, público-alvo e estratégias e procedimentos dos serviços exclusivos da unidade. O mesmo formato de apresentação possui o terceiro capítulo, em que são tratados os mesmos conteúdos, porém referentes aos serviços exclusivos da unidade 1 do acampamento 1 (CADERNO DE CAMPO, 2015).

O último capítulo do módulo teórico do curso do acampamento é dividido em duas etapas. Na primeira, são abordadas questões referentes aos procedimentos e ao regimento interno do departamento de monitoria: 1) comunicação com o departamento de monitoria: os monitores são orientados a manter seus dados pessoais sempre atualizados para facilitar a comunicação com o departamento; 2) preenchimento das disponibilidades: forma de preenchimento on-line do quadro de disponibilidade; prazos e procedimento de desistência da atuação profissional; 3) apresentação pessoal do monitor: procedimentos e condutas referentes aos uniformes, crachá, vestimenta e aparência pessoal; 4) transporte: procedimento do deslocamento de ida e volta do acampamento; 5) chegada e saída dos monitores na unidades do acampamento: horário de chegada para a atuação profissional e procedimentos em caso de atraso; 6) condutas: ações educativas e éticas do monitor e 7) ações para o bem-estar de todos: cuidado com os objetos dos acampantes; procedimentos em caso de emergência de saúde e normas e procedimentos do acampamento (MANUAL, 2015).

Após a explanação desses procedimentos, é organizada uma dinâmica, em que os participantes são divididos em pequenos grupos e são orientados a apresentar uma pequena cena de teatro que aborde alguma(s) das questões trabalhadas. Após a apresentação de cada grupo, é realizada uma discussão a respeito do assunto que foi abordado (CADERNO DE CAMPO, 2015).

Na segunda etapa do último capítulo, é apresentado um novo serviço do acampamento, o Portal dos Assistentes. O serviço é destinado aos profissionais do departamento de monitoria do acampamento e tem o objetivo de criar uma rede on-line de contato com os funcionários da instituição, no intuito de facilitar a convivência e orientação da equipe (CADERNO DE CAMPO, 2015).

O módulo prático, que acontece nas demais dependências do acampamento, é 
dividido em duas partes: "Treinamento Operacional" e "Módulo Vivencial". Enquanto nas atividades do Módulo Vivencial todos os participantes do curso são envolvidos, no Treinamento Operacional, as atividades são destinadas a categorias específicas de monitores. O Módulo Vivencial acontece duas vezes no curso e nele os participantes vivenciam atividades recreativas que serão utilizadas nas temporadas que ocorrerão ao longo do ano (CADERNO DE CAMPO, 2015).

No Treinamento Operacional, os participantes são divididos em dois grupos: mo- nitores de categoria MET1 e ME1 e monitores de categoria ME2 e ME3. O primeiro grupo é composto por novos monitores e monitores com pouca experiência. No Treinamento Operacional desse grupo, são desenvolvidos conteúdos referentes aos procedimentos operacionais e à orientação de segurança das atividades recreativas do acampamento, que são divididas em três grupos. O quadro a seguir nos mostra o grupo de atividade e as atividades que o compõem (CADERNO DE CAMPO, 2015):

Quadro 2: Grupos e suas atividades

\begin{tabular}{|l|l|l|}
\hline Atividades de rotina do dia & $\begin{array}{l}\text { Atividades de livre esco-- } \\
\text { Iha }\end{array}$ & Atividades de maior risco \\
\hline Alvorada & Charretes & Caiaque \\
\hline Visita do monitor de quarto & Futebol & Cama elástica \\
\hline Horário de livre escolha & Ginásio & Equitação \\
\hline Refeições & Pedalinho & Hover Board \\
\hline Pós-refeições & Pesca & Parede de escalada \\
\hline Atividades dirigidas & Salão de jogos & Ofurôs \\
\hline Baladas e festas & Taco & Piscina do tobogã \\
\hline Lanche da tarde e lanche notur- \\
no & Touro Mecânico & Piscina semiolímpica \\
\hline Recolher & Trenzinho & Tobogã \\
\hline Dormir em chalés & Videokê & Tirolesa \\
\hline- & - & $\begin{array}{l}\text { Trilhas e passeios dentro do } \\
\text { acampamento }\end{array}$ \\
\hline- & - & Passeios fora do acampamento \\
\hline
\end{tabular}

Fonte: MANUAL, 2015.

O conteúdo passado ao outro grupo, composto pelos monitores das categorias ME2 e ME3, refere-se aos procedimentos operacionais de duas atividades recreativas específicas, uma vez que são essas categorias as responsáveis por organizar e supervisionar as atividades durante as temporadas que ocorrem ao longo do ano (CADERNO DE CAMPO, 2015).

Percebemos que a estrutura curricular de ambos os cursos é semelhante. Interessan- te destacar que, enquanto as atividades teóricas acontecem dentro de "salas de aula", as atividades práticas são realizadas fora delas.

No curso a gente trabalha tanto a parte teórica que é feita dentro de sala de aula, como a parte prática, realizada do lado de fora. Então a gente monta as atividades de acordo com a programação do curso, 
tendo as duas coisas, para não ficar uma coisa maçante, só dentro de sala (E2).

A parte teórica é realizada em um auditório, e a parte prática, que consiste em ensinar algumas atividades que serão aplicadas durante as temporadas futuras, são aplicadas nos outros espaços do acampamento (E4).

Melo e Alves Junior (2003) sugerem que as ações de formação não devem preocupar-se exclusivamente com a discussão teórica em sala de aula. De acordo com os autores, ao assumir a função de educar as sensibilidades, a formação de profissionais pode possibilitar experiências que ampliem as vivências culturais dos sujeitos. Dessa forma, para além de um agrupamento de disciplinas estabelecidas por procedimentos, métodos e objetivos, entendemos o currículo como algo repleto de intencionalidades que selecionam e determinam saberes.

No entanto, notamos que os conteúdos práticos e teóricos são abordados de maneira separada em ambos os cursos. Concordamos com Isayama (2010), para quem essa relação de conteúdos deve ser trabalhada de forma unitária, de modo que um sólido referencial teórico possibilite a compreensão da prática através de novos olhares, adquirindo assim função diferente de um simples fazer mecânico e técnico. É comum encontrar em diversas ações de formação em lazer propostas nas quais a prática torna-se eixo central do processo e sua realização acaba por minimizar o papel da teoria na ação profissional. Segundo Gomes (2008):

Quando a formação é fundamentada nessa perspectiva, por meio do consumo puramente técnico de um rol de práticas recreativas, da ênfase no conhecimento de um número determinado de jogos e brincadeiras, bem como da compra alienada de bens/serviços, são feridos os princípios de autonomia dos sujeitos e fica limitado o potencial teórico-prático lúdico, crítico, criativo e interdisciplinar que pode ser vivenciado nessas experiências (p. 80).

Baseado em Tardif (2008), acreditamos que propostas curriculares desse tipo devam fundamentar-se em um ensino que enfatize o exercício da profissão, que se preocupe com o ensino de conteúdos através do processo do "saber-fazer", na tentativa de romper a dicotomia teoria-prática. Nesse sentido, Schön (1992) salienta que, pelo fato de estar intimamente encarnado na ação, o conhecimento é sempre uma relação estabelecida entre a prática e as interpretações que dela fazemos. Para o autor, a teoria nada mais é que o "conhecimento na ação".

Marcellino (2003) nos alerta sobre a existência de cursos de formação que abordam a temática do lazer baseando-se em visões genéricas do tema, tendo como objetivo a habilitação de "especialistas tradicionais". Nesse sentido, percebemos que, tanto na parte prática quanto na teórica dos cursos pesquisados, existe a preocupação em ensinar atividades, procedimentos e condutas que as instituições julgam ser ideais para o funcionamento das atividades. De acordo com o entrevistado E2:

A parte prática tem o objetivo de ensinar as atividades recreativas para os futuros monitores. Como que eles vão saber orientar as crianças nas temporadas? O melhor jeito de aprender as atividades é brincando (E2).

Notamos que o tipo de formação que ambos os acampamentos se propõem a oferecer aos seus profissionais é ancorado em uma perspectiva que enfatiza a formação técnica, orientada pelo domínio de conteúdos específicos e preocupada com a instrumentalização e com o domínio de procedimentos e metodologias. 
De acordo com Santos (2011), muitas vezes, nos seus diferentes níveis e espaços, as ações de formação profissional em lazer são caracterizadas e questionadas como ações que levam a uma formação instrumentaliza$\mathrm{da}$, que enfatiza a "aprendizagem de receitas de jogos e brincadeiras além da reprodução de técnicas para atuar em diferentes espaços" (SANTOS, 2011, p. 19). Nesse sentido, Isayama (2010) nos apresenta uma realidade relacionada aos currículos de ações de formação em lazer em que:

A preocupação central é com a instrumentalização técnica e com o domínio de procedimentos e metodologias. Como resultado surge o tecnicismo que restringe o profissional a um "simples" técnico e a mediação técnica se torna substantiva, norteando os fins e valores do processo de formação e não ao contrário. A prática torna-se o eixo da formação e sua realização tende a minimizar o papel da teoria na ação profissional (p. 12).

Concordamos com Paraíso (2010, p. 50), quando afirma que "o currículo pode ser entendido como um artefato envolvido em relações de poder de diferentes tipos que apresenta um conjunto de saberes para serem ensinados a alguém que se deseja transformar, modificar, subjetivar e governar". Por intermédio do relato a seguir, percebemos conexões com a afirmação realizada pela autora:

Nossa preocupação é realmente ensinar aos monitores a sua função dentro da filosofia do acampamento. Quais que são as funções principais desse monitor, quais que são os cuidados principais, quais que são a posturas e responsabilidades principais. Você precisa que um monitor seja extremamente alegre, extremamente cativante, que seja extremamente bem aceito pela criança, mas antes do que isso você precisa de um monitor responsável, maduro e consciente do que está fazendo (E1).

Rose (2001, p. 41) atenta para a existência de propostas curriculares de formação profissional em lazer apoiadas em princípios que chama de "programas e estratégias mais ou menos racionalizadas para a conduta da conduta", na qual, por meio de uma "pedagogia padronizada” (GIROUX, 1995), "especialistas tradicionais" (MARCELLINO, 1995) estão sendo colocados no mercado de trabalho.

Pelo fato de o currículo ser um artefato produtor de sujeito (PARAísO, 2010) e, por conseguinte, capaz de gerar efeitos no tipo de sociedade em construção, a escolha sobre que saberes selecionar, que significados priorizar e que estratégias adotar deve ser feita de maneira cuidadosa. De acordo com a autora, apesar de domínio, regulação e governo se entrecruzarem no currículo, nele também "pessoas, forças e objetos se encontram, conquistam, experimentam, produzem, revitalizam, aumentam a potência de agir ou a força de existir" (p. 55).

Nesse sentido, Silva (2013) complementa afirmando que o currículo é um "documento de identidade" que está estreitamente relacionado ao nosso processo de formação e às nossas trajetórias de vida, e postula que, "no curso dessa corrida que é o currículo, acabamos por nos tornar o que somos" (p. 15). O currículo vai para além do âmbito do conhecimento, como descreve o autor:

\footnotetext{
Nas discussões cotidianas, quando pensamos em currículo, pensamos apenas em conhecimento, esquecendo-nos de que o conhecimento que constitui o currículo está inextricavelmente, centralmente, vitalmente, envolvido naquilo que somos, naquilo que nos tornamos: na nossa identidade, na nossa subjetividade (SILVA, 2013, p. 15).
} 
Defendemos, dessa forma, a construção de currículos que contribuam para a produção de sujeitos capazes de questionar e criticar aquilo que foi significado.

\section{OS SABERES E COMPETÊNCIAS NO CURRÍ- CULO DOS CURSOS}

Os processos de formação no âmbito do lazer devem trabalhar questões relacionadas aos saberes e competências dos profissionais, de modo a enfatizar o reconhecimento tanto do campo do lazer quanto dos outros sujeitos, como construção compartilhada por todos os sexos, idades, etnias, camadas sociais e sujeitos portadores de necessidades diversas. Nesse sentido, Pinto (2001, p. 69), salienta que "a alegria que se constrói nesse compartilhar é a totalidade do sujeito que sente, compreende, age, mudando algo no mundo".

Assim, baseamos o conceito de educação para o lazer na perspectiva apresentada por Marcellino (1995), na qual o lazer, vivenciado em tempo e espaço disponíveis para a vivência lúdica, é concebido como fenômeno social e componente da cultura historicamente situada. Pinto (2001, p. 59) complementa afirmando que o lazer é um importante "espaço educativo construído por meio de interações prazerosas centradas no sujeito".

Tardif (2002) afirma que os saberes, construídos na própria esfera social, são provenientes de variados contextos, oriundos, por exemplo, da sociedade, da instituição escolar, dos atores educacionais e da universidade. Nesse sentido, França (2010) nos apresenta a seguinte definição de saber:

...o saber orienta a visão de mundo extraída de realidades concretas que descrevem os cenários políticos e socioeducativos das experiências formativas, curriculares, disciplinares, mas, sobretudo, culturais da experiência vivida pelo profissional, o que significa socializar pensamentos que distinguem e unem descobertas do lazer por meio de práticas livres, críticas, autocriativas, cria- doras e culturais; significa propor ideias de cunho revolucionário nas quais os sujeitos, autores do seu que fazer, elaboram, sistematizam e recriam práticas nas mais diferentes formas (p. 107).

Leite (1996) nos apresenta três eixos nos quais os saberes - cercados por uma gama de competências que permeiam o esboço de um perfil ideal para a atuação profissional - podem ser traduzidos: 1 ) saber fazer: relacionado às dimensões práticas e técnicas; 2) saber ser: inclui traços de personalidade e caráter, como a capacidade de iniciativa, comunicação, valores, produtividade, mudanças e inovação, que ditam os comportamentos nas relações sociais de trabalho; 3 ) saber agir: capacidade de intervenção e/ou decisão diante de eventos específicos, como trabalho em grupo, solução de problemas e sugestão de ideias.

O trecho apresentado a seguir diz respeito a uma "descrição sumária" dos saberes esperados dos profissionais do Acampamento 1.

Promovem atividades recreativas diversificadas, visando ao entretenimento, à integração social e ao desenvolvimento pessoal dos clientes. Para tanto, elaboram projetos e executam atividades recreativas; promovem atividades lúdicas, estimulantes à participação; atendem clientes, criam atividades recreativas e coordenam setores de recreação; administram equipamentos e materiais para recreação. As atividades são desenvolvidas segundo normas de segurança (MONAC, 2015, p. 5).

É preciso tomar cuidado ao conceber o lazer como mercadoria, ${ }^{1}$ seguindo uma ten-

\footnotetext{
O lazer sob essa perspectiva é visualizado como um produto com potencial para ser comercializado. Assim, em nossa realidade, estamos sujeitos a nos tornarmos reprodutores de cultura, quando o lazer é limitado à repetição e ao consumo alienado do divertimento, minimizando as oportunidades de liberdade, imaginação e construção coletiva.
} 
dência do entendimento da educação para o lazer de forma diferente da já apresentada. De acordo com Pinto (2001), nessa concepção, o lazer

...é carregado do sentido de atividade, cumprindo com as funções de descanso, divertimento e desenvolvimento social com fins moralista (canalização das tensões e redução dos problemas sociais, atuando como válvula de escape e segurança da sociedade), compensatório (manutenção do status quo e descanso voltado à recuperação da força de trabalho) e utilitarista (instrumento de paz social e de mercadoria - entretenimento que demanda o consumo de atividades, bens e serviços) (p. 55).

O cotidiano passa a ser considerado como objeto da organização social e o lazer integrado ao consumo dirigido, requerendo não apenas a organização do cotidiano, mas também sua programação. Pinto (2001, p. 56) salienta que o lazer passa a ser atrelado ao sentido de "tempo livre" ou "tempo disponível" se compreendido "com o sentido de consumo de atividades recreativas organizadas, supervisionadas e difundidas por intervenções educativas desenvolvidas em tempos e espaços diferentes".

A seguir, apresentamos trechos das entrevistas realizadas, onde é possível encontrar pistas de como os saberes e competências são trabalhados nos cursos pesquisados.

Durante o curso, a partir de uma descrição detalhada, fazemos com que eles aprendam de forma profunda suas funções. O que devem fazer, na hora, no local e com os materiais certos (E2).

Nosso curso visa o que realmente vai ser usado nas temporadas. Os aspectos práticos da atuação.
Então, os conteúdos procuram atender as necessidades de cada momento mesmo que nós estamos passando (E3).

A partir dos relatos dos entrevistados, percebemos que não existe uma perspectiva crítica no conteúdo dos cursos. A metodologia utilizada é essencialmente prática/recreativa, o que dificulta pensar o lazer em suas diversas interfaces.

Nesse sentido, Pinto (2001) nos apresenta o conceito de "recreação orientada", a qual, na tentativa de manter os sujeitos dentro dos limites das normas morais e dos valores estabelecidos socialmente, tem o objetivo de organizar o tempo de lazer das pessoas por meio de diferenciadas intervenções que consideram cada grupo e camadas sociais.

Nesse sentido, Marcellino (1995) e Pinto (2000) apontam três ideias que ajudam na compreensão da recreação orientada e sua característica vertical na organização e no controle das ações propostas: 1) a vivência fundada no prazer pela "atividade com o fim em si mesma"; 2) caracterizada como "atividade/meio" e 3) destacada como "liberdade vigiada”. De acordo com os autores, enquanto nas duas primeiras ideias a recreação não integra os currículos como objeto da educação, nem é considerada como parte de objetivos educacionais, na terceira a orientação e a motivação são confundidas com um simples "deixar fazer".

A partir da fala dos entrevistados, fica clara a existência de uma estrutura organizacional piramidal no trabalho dos acampamentos, o que, segundo Isayama e Sá (2006), acaba por hierarquizar a relação entre os sujeitos e sua atuação profissional. Menicucci (2006) propõe a substituição desse modelo por estruturas matriciais flexíveis, que permitam a coordenação constante em todos os níveis, por meio da participação de todos os sujeitos envolvidos nas ações profissionais. Na organização piramidal, os pilares básicos para a atuação dos profissionais dos acampamentos passam a ser a tolerância, a animação 
e o prazer pelo trabalho (ISAYAMA, 2010), uma vez que as ações de lazer são pensadas e elaboradas pelos coordenadores e/ou diretores e executados pelos monitores, excluindo os últimos do processo geral de criação da programação proposta. De acordo com Stoppa (1999, p. 35), dessa forma exclui-se "a participação das pessoas que são alvo das atividades, ignorando seus desejos e suas expectativas, impondo, desse modo, modelos e horários específicos para a realização da programação de 'lazer"”.

Stoppa (1999) nos alerta sobre a prevalência, em muitas intervenções para a formação em lazer, de ações baseadas no ensinamento de pacotes de lazer. Segundo o autor, esses pacotes "são criados como receituário nos gabinetes para o simples consumo, procurando preencher todo o tempo de seu público-alvo com as atividades programadas" (p. 35).

É possível notar que esses tipos de ações possuem o intuito de qualificar os participantes no que se refere ao aprendizado de atividades, para facilitar a vivência do público-alvo de sua ação (ISAYAMA, 2010). De acordo com Stoppa (1999, p. 34), esse profissional geralmente não estabelece uma prática, "mas sim um tarefismo, além de confundir a prática do lazer, com a prática profissional que o lazer requer, pois o profissional desconhece a teoria do lazer, reduzindo sua atuação a um fazer não-refletido".

Arantes e Dias (2012) entendem as competências como a correlação de um conjunto de conhecimentos, habilidades e atitudes, que podem ser aferidos e que afetam a maior parte de uma tarefa, de um papel ou de uma responsabilidade relacionada ao desempenho de determinada função. De acordo com Ungheri (2014, p. 50), é possível "quantificá-las no sentido de apontar futuras ações de treinamento e desenvolvimento para aperfeiçoamento daquelas tidas como deficitárias ou com potencial de melhoria".

Nesse sentido, Pinto (2001) apresenta quatro grupos de competências que julgamos coerentes para uma atuação profissional de qualidade no âmbito dos acampamento de férias: 1) referentes ao comprometimento com os valores inspiradores da sociedade democrática; 2) referentes à compreensão do nosso papel social na educação para o lazer; 3) referentes ao domínio dos conteúdos a serem socializados e de seus significados em diferentes contextos e articulações interdisciplinares e 4) referentes ao domínio de conhecimento pedagógico e de processo de investigação que possibilitem o aperfeiçoamento da prática pedagógica e o gerenciamento do próprio desenvolvimento de ações educativas lúdicas.

Com o mesmo propósito, apresentamos algumas competências que os acampamentos pesquisados julgam como ideais para uma intervenção profissional de qualidade. Uma das competências esperadas pelo Acampamento 2 é a:

Iniciativa do bom senso: iniciativa
que o monitor apresenta para resol-
ver as situações com que se depara
(se a considera e tenta buscar solu-
ções de ajuda ou se as desconside-
ra, deixando sem solução) e qual a
qualidade das soluções encontra-
das (se houve bom senso) (MANU-
AL, 2015, p. 9).

Ao pensar em bom senso, pensamos nas competências enquadradas no grupo das que se referem ao comprometimento com valores inspirados da sociedade democrática. Nesse sentido, acreditamos que para uma atuação de qualidade não basta somente ter bom senso. De acordo com Pinto (2001, p. 66), “O bom senso supõe que haja apenas um senso - o 'bom'. No entanto, a modernidade nos ensinou que o senso é plural, que a educação e o lazer são lugares de conflitos, que não há como desqualificar a posição do outro".

A partir das experiências construídas em suas vivências, os acampamentos podem ser espaços de constituição de sujeitos e de produção de contextos. Os entrevistados dos dois acampamentos compartilham da ideia de que a experiência é essencial para uma ação profissional de qualidade: 
Você tem que ter uma experiência, um conteúdo a passar pela experiência prática daquilo. Acho que isso tudo vem da experiência prática, da experiência vivida na atuação. A experiência pratica é o mais importante hoje (E3).

Ele tem que ter a prática e a experiência dessa atividade. Ele tem que falar com bagagem, com conhecimento de causa. Não adianta ele só teorizar. Precisa ter vivido, experimentado (E1).

Relacionamos essa competência ao grupo das competências referentes ao domínio dos conteúdos a serem socializados e seus significados em diferentes contextos e articulações interdisciplinares. De acordo com o Manual do Acampamento 2, é imprescindível que o profissional cumpra os procedimentos operacionais do acampamento. Deste modo, Pinto salienta que não basta ter experiência:

As experiências vividas precisam ser potencializadas com o desenvolvimento da criatividade, da curiosidade, da busca do novo. Neste sentido, é fundamental a busca da autonomia dos educandos nas tomadas de decisões sobre a eleição dos conteúdos, abordagem metodológica, criação de diferentes tempos e espaços de vivência lúdica, mobilização de recursos múltiplos desvelados nas interações culturais lúdicas, não se esquecendo da importância da riqueza das diferentes experiências dos educadores, educadoras e educandos os sujeitos [sic] têm experiências diferenciadas. Na educação pelo e para o lazer, é importante valorizar a história do outro - o que traz - e a recriação cultural coletiva. Além disso, não dá para pensar que a educação pelo e para o lazer ocorre na prática - errando e acertando. O saber experiencial precisa ser alimentado com outros saberes, que podem servir de apoio para novas reinvenções e de trocas de experiências que fortalecem lideranças e equipes interdisciplinares (PINTO, 2001, p. 68).

Relacionada ao grupo das competências que se referem ao domínio do conhecimento pedagógico, ao conhecimento de processos de investigação que possibilitem o aperfeiçoamento da prática pedagógica e ao gerenciamento do próprio desenvolvimento de ações educativas lúdicas, por isso, não é suficiente ter apenas o domínio técnico dos procedimentos. De acordo com Pinto:

A educação pelo e para o lazer não pode ocorrer alheia à formação moral fundada na ética lúdica e no gosto estético, bem como no conhecimento de processos de investigação que possibilitem o aperfeiçoamento da prática pedagógica; não pode ser alheia à participação coletiva e cooperativa na elaboração, gestão, desenvolvimento e avaliação dos projetos educativos (PINTO, 2001, p. 69).

Concordamos com Gomes (2008), para quem não basta conceber os profissionais que atuam com o lazer como simples reprodutores. "Os profissionais têm de ser agentes de mudanças capazes de abalar e promover uma reflexão sobre vários fundamentos cristalizados socialmente em nossa cultura; repensar os limites e as possibilidades da situação na qual se encontram" (p. 137). Acreditamos que os profissionais devam ser capazes de, além de analisar possíveis contradições, identificar horizontes de manobras e suportar determinados conflitos e incertezas, mesmo que para isso seja necessário correr riscos.

Por fim, identificamos na fala de um dos entrevistados do Acampamento 1 a ques- 
tão cultural como um dos pilares básicos para o exercício profissional.

São culturas diferentes, então a gente tem que conhecer culturas, conhecimentos gerais total, a gente tem que saber falar a língua da criança, tem que saber falar a língua do pai. Uma coisa que nós ensinamos no curso é exatamente isso. Na parte pedagógica, você vai pegar um grupo na faixa etária de 4 a 7 anos, por exemplo, e tem que saber o que eles estão vendo hoje em dia na televisão. $O$ que eles estão aprendendo? O que ouvem de musica (E2).

As questões culturais estão relacionadas às competências relacionadas à compreensão do nosso papel social na educação para o lazer. Pinto (2001) não nega a sua importância, porém salienta que não basta apenas dominá-la.

De que sentido de cultura falamos? Da "alta" cultura? Da "cultura de massa"? Da "cultura popular"? Precisamos saber um pouco mais sobre as referências culturais dos nossos contextos educativos; compreender as relações entre o processo educativo vivido na escola, em outros contextos educativos e o contexto sociocultural mais amplo em que estão inseridas essas práticas educativas; promover uma prática educativa que leve em conta as características dos educandos, de seu meio social, seus temas e necessidades do mundo contemporâneo; motivar a formação de grupos de interesses culturais no lazer, criando condições para a diversificação e a democratização de múltiplas vivências de conteúdos culturais, ampliando possibilidades para os sonhos, as experiências, as apro- priações e as recriações de saberes. O lazer é um dos lugares dos nossos projetos e aventuras, momento de nos expandirmos em todo tipo de expressão e de viver a unidade entre o que sentimos, pensamos e fazemos (p. 67).

Portanto, os processos de formação no âmbito do lazer devem ser fundados em uma prática profissional que pensa sobre os sentidos da sua ação, questiona-se a respeito de possibilidades de alternativas para determinadas situações, planeja e avalia os resultados de forma coletiva. Nesse sentido, Gomes (2008) afirma que:

...uma sólida formação profissional voltada para o lazer não esta, pois, comprometida com o simples processo de transmissão de saberes, mas de construção e posicionamento de nossa própria constituição enquanto sujeitos, e de nosso papel nos seio das diversas divisões socioculturais inscritas em nossa realidade (p. 140).

Por isso, o desafio é ampliar a luta por uma formação profissional multi/interdisciplinar, na qual os profissionais estejam, além de preparados e criticamente alinhados, inquietos por mudança e transformação nas vivências de lazer presentes na atualidade.

\section{CONSIDERAÇÕES FINAIS}

Verificamos que os cursos dos dois acampamentos pesquisados possuem uma estrutura organizacional semelhante. Ambos possuem a duração de três dias e ocorrem nas dependências dos próprios acampamentos. Os acampamentos diferenciam-se quanto aos motivos que os levaram à criação dos cursos de formação. Enquanto o curso do Acampamento 1 foi criado devido à dificuldade em buscar mão de obra qualificada para atuar no campo do lazer, o curso do Acampamento 2 foi motivado pela demanda de serviços e pela 
necessidade da qualificação de uma equipe que aumentava.

Identificamos que o modelo de profissional procurado para atuar no segmento é aquele que é jovem, sabe comunicar-se e é capaz de aplicar as atividades aprendidas. Além disso, busca-se o profissional animado, tolerante e que ama o que faz. Esses critérios confirmam o pensamento de que o perfil profissional procurado para atuar com o lazer nem sempre está relacionado com a formação específica e aprofundada sobre a temática, mas sim com questões de aceitação da filosofia do local, questões estéticas e de tolerância.

Verificamos que ambos os cursos de formação possuem uma estrutura curricular semeIhante, na qual módulos teóricos e práticos são abordados separadamente. O tipo de formação que ambos os acampamentos propõem-se a oferecer aos seus profissionais é apoiado em uma perspectiva que enfatiza a preocupação com uma formação técnica, orientada pelo domínio de conteúdos específicos e preocupada com a instrumentalização e com o domínio de procedimentos e metodologias.

Detectamos a existência de uma estrutura organizacional piramidal no trabalho dos acampamentos, que hierarquiza a relação entre os sujeitos e sua atuação. Dessa forma, as atividades de lazer utilizadas ao longo das temporadas dos acampamentos são pensadas pelos coordenadores e executadas pelos monitores, que não participam do processo de criação da programação. Esse tipo de estrutura organizacional pode reforçar a dicotomia teoria/prática na atividade dos acampamentos de férias. $O$ mesmo acontece nas atividades realizadas ao longo dos cursos, que têm o intuito de qualificar os participantes no que se refere ao aprendizado de atividades, para facilitar a vivência do público-alvo de sua ação. Nesse sentido, esse tipo de organização poderia ser substituído por estruturas organizacionais mais flexíveis, que permitam a coordenação constante em todos os níveis hierárquicos, por intermédio da participação dos sujeitos envolvidos nas ações profissionais.

Por fim, este estudo pode auxiliar na compreensão do debate a respeito da formação profissional em lazer e suas conexões com os estudos curriculares. Assim, o currículo da formação profissional em lazer pode ser entendido tanto como um texto cultural, como uma prática de significação, quanto como um discurso produtivo ou como um texto produtor de sujeitos. A escolha dos saberes, dos significados priorizados e das estratégias adotadas na construção dos currículos possui consequências relevantes na produção dos sujeitos e, consequentemente, no tipo de ação que os acampamentos de férias pretendem desenvolver.

\section{REFERÊNCIAS}

ARANTES, B. O.; DIAS, S. A. A. Competências. In: CASTRO, C. L. F. de; GONTIJO, C. R. B.; AMABILE, A. E. de N. (Org.). Dicionário de Políticas Públicas. Barbacena, MG: EdUEMG, 2012. Disponível em: <http://pt.calameo.com/read/0016339049620b36a7dac>. Acesso em: 10 abr. 2016.

CAMARGO, L. O. L. Recreação pública. Cadernos de Lazer. São Paulo, n. 4, p. 29-36, 1979.

EELLS, E. History of organized camping: the first 100 years. Martinsville, USA: American Camping Association, 1986.

GIROUX, H. A. A Disneyzação da Cultura Infantil. In: SILVA, T. T. da; MOREIRA, A. F. (Org.). Territórios Contestados: o currículo e os novos mapas políticos e culturais. Petrópolis: Vozes, 1995, p. 48-81.

GOMES, C. L. Lazer, Trabalho e Educação: relações históricas, questões contemporâneas, 2. ed. Belo Horizonte: UFMG, 2008. 
HENRIQUES, C. H. Ação profissional no lazer em acampamentos de férias: analisando o planejamento, a metodologia e a avaliação, 2004, 55s. Trabalho de conclusão de curso (Graduação em Educação Física) - Escola de Educação Física, Fisioterapia e Terapia Ocupacional, Universidade Federal de Minas Gerais. Belo Horizonte, 2004.

ISAYAMA, H. F. Formação profissional no âmbito do lazer: desafios e perspectivas. In: ISAYAMA, Helder Ferreira (Org.). Lazer em estudo: currículo e formação profissional. Campinas: Papirus, 2010, p. 9-26.

ISAYAMA, H. F. Recreação e Lazer como integrantes de currículos dos cursos de graduação em Educação Física, 2002. Tese (Doutorado em Educação Física) - Faculdade de Educação Física, Universidade Estadual de Campinas. Campinas, 2002.

ISAYAMA, H. F.; SÁ, E. P. Lazer, empresa e atuação profissional. Brasília: SESI/DN, 2006.

LEITE, E. M. Reestruturação produtiva, trabalho e qualificação no Brasil. In: BRUNO, L. (Org.). Educação e trabalho no capitalismo contemporâneo: leituras selecionadas. São Paulo: Atlas, 1996, p. 146-187.

MAGNANI, J. G. C. Lazer, um campo interdisciplinar de pesquisa. In: BRUHNS, H. T., GUTIERREZ, G. L. (Org.). O corpo e o lúdico: ciclo de debates "Lazer e motricidade". Campinas: Autores Associados, 2000, p. 19-34.

MANUAL de monitoria NR. Sapucaí Mirim: NR Prolíder, 2015.

MARCELLINO, N. C. A formação e o desenvolvimento de pessoal em políticas públicas de lazer e esporte. In: MARCELLINO, N. C. (Org.). Formação e desenvolvimento de pessoal em lazer e esporte: para atuação em políticas públicas. Campinas: Papirus, 2003, p. 9-18.

MELO, V. A. de; ALVES JÚNIOR, E. Introdução ao lazer. São Paulo: Manole, 2003.

MENICUCCI, T. Gestão de políticas públicas: estratégias para construção de uma agenda. IX CONGRESSO NACIONAL DE RECREACIÓN. Bogotá: Colombia, 2006. Disponível em <http:// www.redcreacion.org/documentos/congresog/TMenicucci.html>. Acesso em: $1^{\circ}$. mai. 2016.

MONAC. 49. Ed. Brotas: Grupo Peraltas, 2015.

PARAíSO, M. A. Currículo e formação profissional em Lazer. In: ISAYAMA, H. F. (Org.). Lazer em estudo: Currículo e formação profissional. Campinas: Papirus, 2010, p. 27-58.

PINTO, L. M. S. de M. Em busca do corpo esportista brincante. In: BELO HORIZONTE. Prefeitura Municipal. Secretaria Municipal de Esportes. $O$ lúdico e as políticas públicas: realidade e perspectivas. Belo Horizonte, 1995, p. 43-51.

PINTO, L. M. S. de M. A escolarização da recreação na educação brasileira. CONGRESSO DE EDUCAÇÃO FÍSICA E CIÊNCIAS DO DESPORTO DOS PAÍSES DE LÍNGUA PORTUGUESA, 8, Lisboa/ Portugal, 2000. Anais... Lisboa: [s. n.], 2000.

PINTO, L. M. S. de M. Formação de educadores e educadoras para o lazer: saberes e competências. Revista Brasileira de Ciências do Esporte. Campinas, v. 22, n. 3, p. 53-71, 2001.

ROSE, N. Como se deve fazer a história do eu?. Educação e realidade. Porto Alegre, v. 26, n. 1, p. 33-58, 2001.

SANTOS, C. A. N. L. e. O currículo dos cursos técnicos de lazer no Brasil: um estudo de caso de formação profissional, 2011, 142s. Dissertação (Mestrado em Estudos do Lazer) - Escola de 
Educação Física, Fisioterapia e Terapia Ocupacional, Universidade Federal de Minas Gerais. Belo Horizonte, 2011.

SCHÖN, D. A. Formar professores como profissionais reflexivos. In: NÓVOA, António (Org.). Os professores e a sua formação. Lisboa: Dom Quixote, 1992.

SILVA, T. T. da. Currículo e identidade social: territórios contestados. In: SILVA, T. T. da (Org.). Alienígenas na sala de aula: uma introdução aos estudos culturais em educação, 8. ed. Petrópolis: Vozes, 2013, p. 185-201.

STOPPA, E. A. Acampamentos de férias. Campinas: Papirus, 1999.

STOPPA, E. A. Lazer e mercado de trabalho. Revista Licere. Belo Horizonte, v. 3, n. 1, p. 176-181, 2000.

TARDIF, M. Saberes docentes e formação profissional. Petrópolis: Vozes, 2002.

TARDIF, M. Princípios para guiar a aplicação dos programas de formação inicial para o ensino. In: ENCONTRO NACIONAL DE DIDÁTICA E PRÁTICA DE ENSINO, 14. Anais... Porto Alegre: Ed. da PUC, 2008, p. 17-41.

TRAUTMANN, J. A formação no contexto de uma redução do tempo de trabalho. Revista Europeia: Formação Profissional, n. 23, p. 18-28, mai./ago., 2001.

TRIVIÑOS, A. N. Introdução à pesquisa em ciências sociais: a pesquisa qualitativa em educação. São Paulo: Atlas, 1987.

UNGHERI, B. O. A atuação profissional em políticas públicas de esporte e lazer: saberes e competências, 2014, 132s. Dissertação (Mestrado em Estudos do Lazer) - Escola de Educação Física, Fisioterapia e Terapia Ocupacional, Universidade Federal de Minas Gerais. Belo Horizonte, 2014.

\section{DADOS DOS AUTORES}

\section{Gustavo Schunemann Christofaro Silva}

Graduado em Educação Física pela Pontifícia Universidade Católica de Minas Gerais. MesTRE EM ESTUdOS DO LAZER, PELA ESCOLA DE EdUCAÇÃo FísICA, FISIOTERAPIA E TERAPIA OCUPACIONAL DA UNIVERSIDADE FederAL DE MINAS GERAIS. PRADOS/MG - BRASIL. GUT01804@GMAIL.COM

\section{HELDER FERREIRA ISAYAMA}

Graduado em Educação Física pela Universidade Estadual Paulista Júlio de Mesquita Filho. Mestre em Educação Física pela Universidade Estadual de Campinas. Doutor em Educação Física pela Universidade Estadual de Campinas. Belo Horizonte/MG - Brasil. helderisayama@yahoo. com.br 